\title{
DILEMAS DA EDUCAÇÃO SUPERIOR NO MUNDO GLOBALIZADO: SOCIEDADE DO CONHECIMENTO OU ECONOMIA DO CONHECIMENTO?*
}

\author{
Grupo de Estudos e Pesquisas sobre Educação Superior ${ }^{* *}$
}

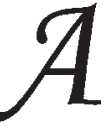

elaboração desta resenha é fruto de discussão ocorrida no Grupo de Estudos e Pesquisas sobre Educação Superior (GEPES), da Faculdade de Educação da UNICAMP. Tendo por objetivo o estudo e a pesquisa sobre questôes da educação superior, o interesse na temática do livro levou o grupo a um amplo e aprofundado debate, resultando na elaboração desta resenha. A organização final do texto teve como autores: Gianna Perim, Sueli Petry Luz, Maria de Lourdes P. de Almeida, Elisabete M. A. Pereira e Arnaldo Santos Di Trani.

Trata-se de um livro abrangente, com pertinentes análises sobre questões que estão postas à educação superior de forma geral. Com base na análise dos marcos econômicos, culturais e sociais, o livro apresenta ao leitor as diferentes razões da forma como está sendo organizada e estruturada a educação superior brasileira, nos últimos tempos. Esta publicação é uma grande contribuição para os estudiosos da área, pois encontram no texto do prof. José Dias uma competente e séria discussão sobre os diferentes dilemas que as mudanças, as realizações e os desafios da crise no nível do Estado, do trabalho e do sujeito apresentam à educação superior, de forma geral, e à educação superior brasileira, de forma específica. É um texto que, como diz o autor, "não trata das certezas, mas das incertezas" (p. 23).

\footnotetext{
* Resenha do livro de José Dias Sobrinho (São Paulo: Casa do Psicólogo, 2005).

** Criado em 28 de outubro de 1992, o Grupo de Estudos e Pesquisas em Educação Superior (GEPES) visa à promoção, coordenação e difusão de estudos e pesquisas na área de ensino superior, através do esforço e cooperação de pesquisadores da Faculdade de Educação e de outras unidades da UNICAMP, além de instituiçôes nacionais e internacionais. Para saber mais sobre o GEPES, visite o site <www.fe.unicamp.br/gepes>
}

Educ. Soc., Campinas, vol. 28, n. 98, p. 281-285, jan./abr. 2007 
Dilemas da educação superior no mundo globalizado...

A obra é apresentada pelo prof. Pedro Goergen, que enfatiza a oportunidade da publicação num momento em que a universidade passa por uma crise caracterizada, em sua opinião, por uma tríplice dimensão: crise conceitual, contextual e textual. A crise conceitual é vista por Goergen como a crise do conceito "universidade", a qual permite o uso deste termo de forma genérica, sem correspondência a uma idéia. A crise contextual diz respeito à relação da universidade com uma sociedade em dinâmicas e profundas transformações pela ciência, tecnologia, globalização econômica, globalização cultural, instabilidade do mercado de trabalho, entre outras transformações. A crise textual está relacionada ao desafio que a universidade enfrenta para preparar profissionais e pesquisadores éticos. Os temas que envolvem os elementos apontados por Goergen como responsáveis pela tríplice dimensão da crise da universidade são aprofundados nos capítulos do livro, com riqueza de análise, permitindo ao leitor uma visão clara das intrincadas relações dos elementos constitutivos da situação atual da educação superior.

$\mathrm{Na}$ apresentação da obra, Dias Sobrinho esclarece que os dilemas da educação superior estão postos pela manifestação da crise estrutural do Estado, que não consegue prover suas instituições das condições necessárias para que se promova a equidade, a justiça social, a democratização. Descreve um cenário composto de contradições, onde se situa o grande dilema da educação superior hoje: educação como direito social e bem público ou educação como negócio e mercadoria.

Com poder de argumentação historicizado, o autor demonstra que o conhecimento científico, neste inicio de século XXI, passa a ser um instrumento de apropriação material e espiritual nas mãos da classe economicamente dirigente, que o usará como meio de extorsão de mais-valia. Separados dos meios de produção de vida material, tal elite produz um saber incoerente com a situação nacional. Descreve que as instituiçóes civis e políticas, nas quais essa elite financeira e política atua, reproduzem um fenômeno inerente à força do capital, resultando em um cenário onde: o Estado não é mais capaz de prover as instituiçôes; a nova economia rompe com os modelos tradicionais do trabalho; e os benefícios da educação globalizada se voltam mais aos indivíduos do que à sociedade.

As questôes do trabalho estão postas nas análises que o autor faz da globalização econômica, as quais apresentam para a educação superior problemas sócio-profissionais e a emergência de novos senti- 
dos que a universidade, da forma como foi estruturada, encontra dificuldades para encaminhar. Embora essa temática perpasse o livro todo, ela é mais explicitamente analisada no Capítulo I - Educação superior, globalização e desafios ético-políticos. Este capítulo busca responder a questão: Que funçōes deve desempenhar a educação superior nesse contexto de incertezas e transformações, em ritmos cada vez mais acelerados? (p. 23) O autor chama a atenção para as responsabilidades da educação superior, afirmando que está em questão o futuro "que não sabemos planejar, mas oxalá seja melhor que o presente que não soubemos ou não conseguimos construir" (p. 23).

$\mathrm{Na}$ análise da inferência da globalização nas ações da educação superior, Dias Sobrinho ressalta que a globalização tem significados ambivalentes. Sua face mais evidente é a dimensão econômica e técnica, mas ela é multidimensional e tem a ver com as dinâmicas interdependentes da cultura, da política, da ética, da ecologia, do local e do universal. Discute, nos diferentes aspectos da globalização, aqueles ligados: às transformações da educação superior (sociedade do conhecimento x economia do conhecimento); às contraditórias visōes de mundo (antinomia entre humanismo e mercado); às emblemáticas defesas por uma educação sem fronteiras (internacionalização e impactos da educação transnacional nos países latino-americanos); e às reformas da educação superior nos países latino-americanos e nos países da comunidade européia.

Acredita que, com a globalização da economia, o ensino superior público domestica sua identidade. Em sua análise, comprova isto pela constante perda de autonomia universitária, principalmente nas atividades que correspondem à investigação cientifica, onde os rumos da pesquisa têm sido decididos, em sua maioria, pelas fontes financiadoras. Deixar o financiamento ao mérito do mercado significa atrofiar e esquartejar as áreas de pesquisas fundamentais e o conseqüente amordaçar do Estado constitucional. Nesse sentido, salienta que os órgãos governamentais, ainda que trabalhando com dinheiro público, tendem a financiar projetos diretamente vinculados aos interesses do setor produtivo.

O autor compreende que a apropriação do conhecimento científico não é um privilégio do atual neoliberalismo, que epidemiza o ethos acadêmico. Por mais público que pareça o modelo de ciência que idealiza um projeto de pesquisa totalmente desvinculado do setor 
Dilemas da educação superior no mundo globalizado...

produtivo, os interesses que a academia atende sempre privilegiam e destinam-se a esse grupo. $\mathrm{O}$ que caracteriza esta forma de apropriação do conhecimento é a abertura ao mercado, o qual redefine as relações entre os "produtores" do conhecimento e os seus "consumidores". Dentro desse ethos acadêmico, os interesses econômicos financiam e dão destino à pesquisa científica. $\mathrm{O}$ confronto ideológico contemporâneo edifica-se com a problemática da legitimidade e legalidade desse processo de mercantilização.

Afirma que os pesquisadores da universidade perdem identidade devido à flexibilização do trabalho, ao enfraquecimento dos sindicatos e ao desmonte do sistema de proteção acadêmica fundada em direitos histórica e arduamente adquiridos. Trata-se de um processo econômico que des-configura diretamente o Estado-nação que, ainda que minimamente, garantia direitos e promovia o "bem estar", de acordo com as urgências político-sociais da sociedade civil.

Outro importante ponto apontado pelo livro é a atenção para o profissional requerido pelo fenômeno da globalização. Este tem grande especialização e está em contínua formação para garantir um lugar na frenética competição do mercado. Todavia, como homem, sofre as conseqüências, pois o mercado apenas o identifica por aquilo que produz. As suas dimensóes humana e social ficaram submetidas à dimensão mercadológica, embora identificada como necessária para o alcance do desenvolvimento do Estado-nação.

O ponto central trazido pelas suas reflexões é o desafio da educação superior para a construção da globalização da justiça e da dignidade humana, da recuperação da dimensão histórica dos indivíduos e da reintegração da sociedade. Analisa que o crescimento econômico, baseado nas conquistas da tecnologia e do conhecimento, por si só não é capaz de garantir equidade social, erradicar os bolsóes de miséria, evitar a degradação ambiental e a violência.

Com muita clareza, aponta que a universidade, na sua configuração clássica ainda predominante, não dá conta de atender às contraditórias demandas atuais, mesmo com sua enorme capacidade de se superar, se adaptar, se transformar e pensar o futuro. As contradições das demandas colocam objetivos totalmente antagônicos para a educação superior, como: formar em toda extensão e com elevada qualidade pesquisadores e profissionais de ponta e, ao mesmo tempo, fornecer a sim- 
ples capacitação para os postos de trabalho menos exigentes; desenvolver a mais avançada e inovadora pesquisa e, por outro lado, oferecer o conhecimento de pronta aplicação; conciliar os valores gerais e permanentes da sociedade democrática com os interesses imediatos e pragmáticos do mercado.

Dias Sobrinho apresenta a necessidade da universidade responder às expectativas, tarefas e funçôes crescentemente alargadas e complexas, ampliadas pela forte demanda de escolarização superior, pela conexão direta da educação com a expansão social da divisão do trabalho e pelo valor econômico do trabalho, sobretudo da pesquisa especializada. Compreender essas contradiçôes e encontrar novos caminhos são os desafios a serem enfrentados por uma instituição que ainda recebe o nome de "universidade", mas é, em muitos sentidos, uma outra instituição.

Após tratar, de forma bastante rica, das questōes relativas à internacionalização e à transnacionalização e seus impactos na educação superior na América Latina, o autor apresenta dois cenários possíveis para a educação superior: adesão automática ao sistema hegemônico da economia global ou respeito aos princípios e ao ethos universitário.

A participação coletiva, respeito à diversidade, compreensão dos contextos sócio-políticos gerais e dos sentidos das mudanças e suas relações são consideradas pelo autor imprescindíveis às transformações, mudanças e reformas da educação superior. Para ele, todo esforço de reforma deve partir de uma compreensão razoável das cenas atuais e dos cenários futuros e não pode ser gestado de fora para dentro. Acredita que a profundidade e a extensão das mudanças vão depender da capacidade reflexiva da comunidade educativa, que, para ele, parece estar bastante fragilizada.

Adverte que a educação superior corre o risco de se dedicar mais às tarefas e demandas de curto prazo, específicas, imediatas e superficiais, do que a problemas e questôes de largo alcance, mais duradouros, mais significativos para a existência social.

Em tempos de tantas incertezas e desesperanças, o livro é um convite irrecusável para aqueles que acreditam na responsabilidade da educação superior, na formação de cidadãos éticos e responsáveis, na consolidação da democratização da sociedade e na redução das desigualdades sociais. 